\title{
Effects of Patterned Electrical Activity on Neurite Outgrowth from Mouse Sensory Neurons
}

\author{
R. Douglas Fields, Elaine A. Neale, and Phillip G. Nelson \\ Laboratory of Developmental Neurobiology, National Institute of Child Health and Human Development, National Institutes \\ of Health, Bethesda, Maryland 20892
}

\begin{abstract}
A noninvasive method of electric stimulation was used in cell culture preparations to determine the effects of patterned electrical activity on the morphology and motility of mammalian central nervous system growth cones. Neurites from dorsal root ganglion (DRG) neurons of fetal mice were allowed to grow under the barrier of an insert placed in culture dishes. The insert confined the cell bodies within separate experimental and control compartments, and provided a means of exciting action potentials in the growing neurites by extracellular current pulses delivered across the barrier. A phasic pattern of stimulation caused immediate retraction of the filopodia and lamellipodium. Further outgrowth was halted and in many cases retraction of the neurite ensued. No changes in morphology or growth cone motility were evoked by electric stimulation when action potentials were blocked with $1 \mu \mathrm{M}$ tetrodotoxin (TTX). These effects depended on the rate, pattern, and duration of stimulation. Phasic stimulation was more effective than stimulation with the same number of impulses delivered at a constant frequency. An important new observation was that cultures exposed to phasic stimulation for several hours contained actively growing neurites with normal growth cones which were insensitive to the stimulus. This apparent accommodation in neurites exposed to chronic stimulation may involve processes that regulate calcium conductance or buffering.

Cessation of neurite outgrowth by action potentials could represent one mechanism linking morphological and functional characteristics in the developing CNS of mammals, by stabilizing the outgrowth of neurites forming appropriate synaptic contacts and leading to the retraction of growth cones from collaterals that have not formed appropriate contacts at the time the neuron enters into a functionally active circuit.
\end{abstract}

In forming appropriate connections between neurons during development, the growth cone of axons and dendrites use physical and chemical features to seek correct pathways through tissues and recognize proper targets (cf. reviews by Kater and Letourneau, 1985; Letourneau, 1987; Dodd and Jessell, 1988; Harrelson and Goodman, 1988; Patterson, 1988; Fields et al., $1989 \mathrm{~b})$. In addition, the functional activity of a neural circuit

\footnotetext{
Received Feb. 12, 1990; revised March 23, 1990; accepted April 25, 1990.

We thank Ian Forsythe for the temperature controlled stage, Sandra Fitzgerald for assistance with cell culturing, and James Haan for contributing to these experiments as a summer research fellow.

Correspondence should be addressed to Dr. R. Douglas Fields, National Institutes of Health, NICHD, Laboratory of Developmental Neurobiology, Building 36, Room 2A21, Bethesda, MD 20892.

Copyright (C) 1990 Society for Neuroscience $0270-6474 / 90 / 092950-15 \$ 03.00 / 0$
}

is critical, particularly in the CNS of mammals, in determining which connections are retained, lost, strengthened, or weakened (e.g., Purves and Lichtman, 1983; Changeux, 1985). This interrelationship between structure and functional performance of the system is likely to involve several mechanisms, but central to neuronal growth and plasticity is the growth cone, which guides neurite outgrowth, transforms into a synapse, and sprouts anew to form additional collateral or preterminal connections under appropriate conditions. If action potentials can affect the motility of growth cones, the pattern of synaptic connections and morphology of the nervous system would be influenced by the pattern of electrical activity in developing neural circuits.

It has been suggested that influx of calcium ions across the neuronal membrane during an action potential could impact second-messenger systems regulating the elongation of neurites or interact with cation-dependent cytoskelctal components that modulate the morphology and motility of the growth cone (Cohan et al., 1987; Mattson and Kater, 1987; Kater et al., 1988). This is supported by experiments with neurons from the buccal ganglia of the snail Heliosoma in culture, where it has been shown that action potentials elicited by intracellular stimulation cause an immediate cessation of growth cone motility (Cohan and Kater, 1986). However, similar studies performed on neuroblastoma growth cones using intracellular stimulation, potassium-induced depolarization, or the calcium ionophore A23187 produced the opposite result: expansion of the growth cone and continued neurite elongation in response to calcium influx (Anglister et al., 1982). More recent evidence suggests that extracellular calcium is not necessary for growth cone motility in rat superior cervical ganglion neurons (Campenot and Draker, 1989). In the visual system of vertebrates, evidence from experiments using tetrodotoxin (TTX) blockade of electrical activity in vivo does not support a direct effect of action potentials on growth cones (Schmidt and Tieman, 1989).

We are not aware of any publications concerning the effects of electrical activity on growth cones of mammalian neurons. Direct evidence of the possible effects of action potentials on motility of growth cones from mammalian CNS is desired, because of structural and developmental differences, as well as differences in the ionic basis of the action potentials in invertebrate and mammalian nervous systems (cf. Hille, 1984). Unfortunately, the small size of mammalian CNS neurons and their growth cones mitigates against the method of stimulation by whole-cell patch or microelectrodes that are suitable for large invertebrate neurons, because mechanical disruption and perturbation of normal intracellular ionic and physiological conditions would be more severe. In experiments reported here, effects of action potentials on growth cone morphology and motility were studied by a noninvasive method of electric stim- 
ulation in dissociated cell cultures of mouse dorsal root ganglion (DRG) neurons. Noninvasive stimulation of neurites was achieved with a 3 -compartment culture chamber which permits neurite outgrowth under the barriers separating the center and side compartments (Campenot, 1977).

This tissue culture chamber has been used previously to investigate activity-dependent plasticity of synapses between DRG and spinal cord neurons (Fields et al., 1988; Nelson et al., 1989, 1990). Those experiments indicated that the more active DRG inputs (i.e., afferents from the side compartment that was stimulated) developed more and stronger synapses compared to DRG inputs from the compartment that was not stimulated. It is difficult to understand how more synapses would have formed from inputs originating from the stimulated side if electrical activity had inhibited growth cone motility and halted neurite outgrowth, as it does in the snail buccal neurons (Cohan and Katcr, 1986). On the contrary, the greater number of synapses from the stimulated side might be interpreted as evidence for increased growth cone motility or sprouting in the presence of increased electrical activity, as has been theorized from other studies (cf. Levy and Desmond, 1985). A resolution to this paradox is suggested by our results, which indicate that although electrical activity does induce changes in growth cone morphology and inhibit motility of mouse DRG neurons, a process of accommodation appears to enable axons to continue outgrowth in the presence of prolonged electrical activity (Fields et al., 1989a).

\section{Materials and Methods}

Culture method. Noninvasive stimulation of neurites was achieved with a 3-compartment culture chamber which permits neurite outgrowth under the barriers that separate the center and side compartments (Campenot, 1977). Chambers were constructed of Teflon inserts and attached with silicone grease to collagen-coated plastic dishes (Fig. $1 A$ ). Neurons dissociated from the DRG of 13-d-old mouse fetuses were plated into the side compartments (cf. Nclson et al., 1989, 1990; Neale et al., 1990), and after 1 week neurites began to emerge from beneath the barrier and enter the central compartment (Fig. 1B). Extracellular stimulation applied across the barrier between one of the side compartments initiates action potentials in the subjacent neurites (Fig. 3D) (Nelson et al., 1989), while neurites growing into the center from the opposite side serve as nonstimulated controls. (As described below, action potentials are not excited in neurons unless processes extend under the barrier.) Campenot chambers were also attached to culture dishes that had a polylysine and collagen-coated coverglass cemented to a hole in the bottom. Outgrowth on this surface was inferior to that on the scratched plastic dish, but these preparations were used for experiments in which maximal optical resolution was desired.

Microscopy. Outgrowth of neurites in the center compartment was observed on the stage of an inverted microscope that was equipped with temperature and $\mathrm{CO}_{2}$ controls (Forsythe and Coates, 1988) and stimulating electrodes fitted into the cover of the culture dish. Temperature was maintained near $37^{\circ} \mathrm{C}$ and varied less than $0.2^{\circ} \mathrm{C}$ during the experiment. Experiments were carried out in the full culture medium containing $5 \%$ horse serum and $30 \mathrm{ng} / \mathrm{ml} \mathrm{NGF}$ (Nelson et al., 1990), superfused with a humidified and warmed mixture of $10 \% \mathrm{CO}_{2}$ in air. The $\mathrm{pH}$ was controlled with a $\mathrm{CO}_{2} /$ bicarbonate buffer system and monitored with an indicator, phenol red, added to the culture medium. Evaporation from the culture dish was prevented by a thin layer of mineral oil. Neurites with active growth cones bearing a distinct lamellipodium or filopodia were selected for investigation. A period of roughly 20 min was provided to assure temperature and $\mathrm{CO}_{2} / \mathrm{O}_{2}$ conditions in the culture dish were stabilized before each experiment. Actively growing neurites could be maintained on the microscope stage for 4-6 hr or more. Data were generally collected for a period of approximately $2 \mathrm{hr}$.

The growth of neurites was monitored with several different techniques to obviate possible effects of photodamage. In early experiments, growth of neurites was measured from $8 \times 10$ in. prints of photomicrographs taken at roughly 5 min intervals using Hoffman modulation contrast microscopy. A $40 \times 0.55$ n.a. long-working-distance objective was used. Growth cones were not illuminated between photographic exposures. Later experiments were performed on a videomicroscopy system, using phase contrast optics $(32 \times 0.40$ n.a. objective $)$, with a low-light-level SIT video camera (Hamamatsu) or a Neuvicon camera (Hamamatsu) illuminated by a low intensity tungsten light source. Images were stored on an optical disk recorder (Panasonic model TQ$2028 \mathrm{~F}$ ) and printed from a Video graphics printer (Sony model UP850). The dim illumination and minimal exposure time permitted data collection at $2 \mathrm{~min}$ intervals without detectable deleterious effects. A total of 128 low-light-level images were rapidly acquired, digitized, and added by an image analysis computer (Hamamatsu DVS 3000) to remove camera noise and intensify the weak signal. Background subtraction and/or contrast enhancement, accomplished by computer processing, further improved these images. Time-lapsed movies were recorded and playcd back for analysis at various specds from the optical disk recorder.

Optical resolution and contrast in the live, unstained growth cones are compromised by the Teflon insert in the plastic culture dish and by the thick optical path through the culture medium and mineral oil. It was necessary to use a long-working-distance condenser of relatively small numerical aperture because of the distance, approximately $4 \mathrm{~mm}$, between the bottom of the plastic dish and the miniature coverglass resting on the insert. To supplement observations on living growth cones, detailed observations on differences in growth cone morphology associated with stimulation were made on chemically fixed neurites using phase contrast microscopy in plastic dishes, and after fluorescent immunocytochemical localization of cytoskeletal proteins or tetanus toxin binding. Preparations on glass coverslips were fixed, the Teflon inserts were removed so that a coverglass could be applicd, and growth cones were examined with computer-enhanced, DIC-videomicroscopy. An oil immersion $63 \times 1.40$ n.a. plan apochromatic objective was used with an oil immersion condenser of 1.4 n.a.

Immunocytochemistry. Changes in structure of the cytoskeleton and plasmalemma of growth cones after stimulation were visualized by rhodamine-labeled antibodies against actin (Accurate Scientific and Chemicon International) and tubulin (Gozes and Barnstable, 1982) and the C-fragment of tetanus toxin (Neale et al., 1988). Rhodamine-labeled phalloidin (Molecular Probes) was used to visualize filamentous actin. Routine immunocytochemical procedures were followed: fixation in 1$4 \%$ paraformaldehyde in phosphate-buffered saline for about $20 \mathrm{~min}$ and a wash with $0.1 \%$ Triton $X-100$ to make cell membranes permeable to antibodies and phalloidin. Primary antibodies were visualized with rhodaminated sccondary antibodics.

Electric stimulation. The intensity of stimulation required to elicit action potentials was determined by recording intracellular responses of DRG neurons in response to stimulation delivered across the barrier. Threshold for eliciting action potentials was between 1 and $5 \mathrm{~V}$. A stimulus of $6 \mathrm{~V}$ was chosen to assure supramaximal stimulation. The resistance under the barrier is approximately $15-20 \mathrm{k} \Omega$. Stimulation was provided by a constant voltage stimulator, equipped with an isolation transformer on the output to exclude DC voltages. Four patterns of stimulation were investigated: a phasic pattern identical to that used in previous studies concerning the effects of electrical activity on the strength and number of synapses formed during development in vitro (Nelson et al., 1989), and a tonic (continuous frequency) stimulus at $2.5 \mathrm{~Hz}, 5$ $\mathrm{Hz}$, and $10 \mathrm{~Hz}$. The phasic stimulus was comprised of 5 biphasic pulses separated by $100 \mathrm{msec}$, followed by a $1.6 \mathrm{sec}$ rest. Each biphasic pulse was composed of $0.2 \mathrm{msec}$ duration positive and negative pulses separated by $4 \mathrm{msec}$ (Fig. $3 D$ ). A constant frequency monophasic stimulus of $0.2 \mathrm{msec}$ pulses was used to investigate the effects of stimulation at different frequencies. Growth cones conditioned by exposure to the phasic pattern of stimulation for approximately $24 \mathrm{hr}$ were also analyzed. Chronic conditioning stimulation was delivered to one of the side compartments inside the cell culture incubator through electrodes fitted into the lid of the culture dishes. Adequacy of the phasic $6 \mathrm{~V}$ pattern of stimulation at the end of the conditioning period was verified by inserting a microelectrode through a hole in the cover of a culture dish to permit intracellular recordings of action potentials in DRG neurons while subjected to the chronic stimulation delivered through the same electrodes used for the conditioning phasic stimulus. The resistance under the barriers of the Campenot chamber insert was unchanged after $5 \mathrm{~d}$ of phasic stimulation. 

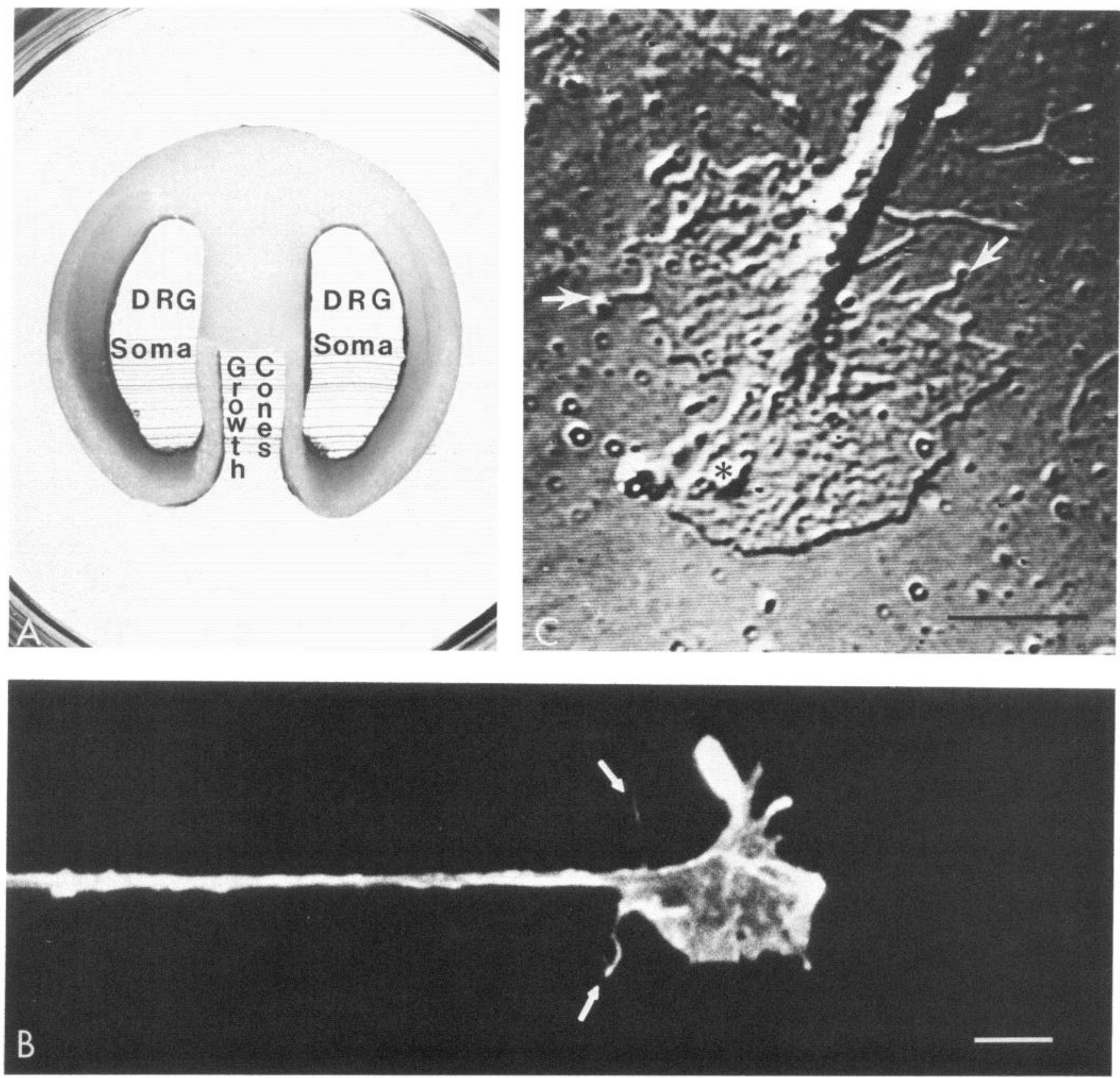

Figure 1. A, Campenot chamber for noninvasive stimulation of DRG axons and visualization of responses in living growth cones. A series of shallow parallel scratches in the collagen-coated $35 \mathrm{~mm}$ plastic dish help direct neurite outgrowth into the central compartment from DRG neurons in the side compartments. Neurites grow under the barrier within a microscopic fluid space beneath a silicone grease seal. This leak-proof seal (15$20 \mathrm{k} \Omega$ ) is created by applying a drop of $1 \%$ methylcellulose to the dish in the area of the scratches before attaching the Teflon insert to the dish. Neurites traversing this barrier can be stimulated by current delivered from extracellular electrodes in the central and side compartments. One side compartment is not stimulated as a control. $B$, The growth cone from a DRG axon that has grown under the barrier is shown after labeling filamentous actin with rhodaminated phalloidin. Relatively large accumulations of filamentous actin are indicated along the margins of the lamellipodium and within filopodia (arrows). $C$, The normal morphology of DRG growth cones is revealed in this micrograph of an unstimulated growth cone which has been cultured on a coverglass-bottomed Campenot chamber. Following fixation with $1 \%$ osmium tetroxide, the growth cone was imaged using DIC-videomicroscopy, with a $63 \times 1.4$ n.a. objective. A total of 128 images were digitized, integrated, and computerprocessed for enhanced contrast. Note the numerous slender filopodial extensions (arrow) from the margin of a broad lamellipodium (*). Scale bars, $10 \mu \mathrm{m}$.

Data analysis. Growth rates were calculated as the slope of the linear regression of distance of outgrowth over time. The significance of differences in slope before and after the onset of stimulation was assessed with an $F$-test, and the significance of differences in mean values was tested by a paired $t$-test (Sokal and Rohlf, 1981). Multiple comparisons of growth rates for different types of stimulation were analyzed by oneway analysis of variance (ANOVA). Calculations for data analysis were performed with the assistance of a computer program (Minitab).

\section{Results}

\section{Phasic stimulation}

Active growth cones with a thin lamellipodium spanning 5-20 $\mu \mathrm{m}$ and bearing numerous slender filopodia were observed at the ends of neurites growing under the barrier into the central compartment (Fig. 1, B, C). These neurites grew at a constant 
rate throughout the period of observation (more than $4 \mathrm{hr}$ in some experiments). Within minutes of switching on the phasic stimulus most filopodia contracted, and the lamellipodium withdrew into the end of the neurite, leaving a blunted terminal (Fig. 2). These changes were seen with several forms of microscopy (Hoffman modulation, phase contrast, and DIC-videomicroscopy, and with extremely low-light-level images detected by computcr addition of 128 images from a SIT camcra). These morphological changes seen in living, unstained preparations were confirmed by comparing the morphology of growth cones from the stimulated and nonstimulated sides of dishes fixed with $\mathrm{OsO}_{4}$ and observed with phase contrast or DIC-videomicroscopy (Fig. 3, B, C), or fixed with paraformaldehyde and processed for visualizing the cytoskeletal protein actin (Fig. $1 B$ ), tubulin (data not shown), or the membrane receptor for the tetanus toxin binding fragment- $C$ (data not shown). The effects of stimulation were not necessarily restricted to the growth cone. Varicosities in the preterminal axon also showed retrograde displacement and the diameter of the axonal terminal often decreased.

Accompanying the changes in growth cone morphology was an abrupt inhibition of outgrowth. Outgrowth was arrested immediately in some growth cones, or within 15 min of stimulation in others. Some retraction of the neurite usually occurred, and in some cases this progressed to complete resorption of the neurite. Figure $3 A$ illustrates 3 typical responses to the onset of phasic stimulation. Although there was some variability in responses of individual growth cones to the phasic stimulus, in the time required to stop outgrowth, or in the extent of axonal retraction, all growth cones exhibited an abrupt retraction of the filopodia and lamellipodium to various degrees with stimulus onset. Without exception, the phasic stimulation halted axonal outgrowth completely (or initiated retraction) within 15 min of stimulation (Table 1). Stopping the stimulus after this period did not restore axonal outgrowth or lead to recovery of normal growth cone morphology within an additional $30 \mathrm{~min}$.

For quantitative analysis, the rate of outgrowth was compared before and after the onset of stimulation using the slope of a linear regression of distance grown over time. These growth rates are summarized in Table 1 , which indicates a reproducible response to the stimulus from a positive slope (representing growth) prior to the stimulus to a negative or horizontal slope after stimulation. In most cases this change in slope for each growth cone was statistically significant with an $F$-test, but outgrowth showed no correlation with the time the preparation had been maintained prior to stimulation. In some experiments growth cones from the experimental side and the control side were visible in the same microscope field. Phasic stimulation invariably stopped the growth cone from the stimulated side, but did not affect the growth cone from the control side. Subsequent stimulation of growth cones from the control side caused them to stop or retract. The mean growth rate for all growth cones measured before stimulation was not significantly different from the growth rate of controls (i.e., neurites from the barrier opposite the one stimulated), but after stimulation growth rates changed significantly, from a mean of $+0.29 \mu \mathrm{m} / \mathrm{min}$ to -0.43 $\mu \mathrm{m} / \min (p<0.02 ; t$-test) (Fig. 4). This indicates that inhibition of growth rate was associated with electrical activation of neurites, rather than a generalized change in conditions brought about by electrical stimulation or degradation over time. Moreover, neurite outgrowth continued in the presence of electrical stimulation, provided $1 \mu \mathrm{M}$ TTX was included in the incubation medium (Fig. 5). Thus, activation of voltage-dependent sodium channels was necessary to initiate the inhibitory response of growth cones to stimulation.

\section{Effects of different patterns of stimulation}

When the same number of impulses were delivered in a constant frequency stimulus (tonic stimulation at $2.5 \mathrm{~Hz}$ ), the inhibition of neurite outgrowth was more variable (Fig. 6). In some instances outgrowth was stopped, but in others a delayed inhibition was seen or no inhibition occurred (Table 2). Two growth cones stimulated at $5 \mathrm{~Hz}$ also failed to stop their outgrowth, but the growth cones did exhibit some of the regressive changes in morphology described above. At $10 \mathrm{~Hz}$ tonic stimulation, neurites retracted in 3 out of 4 cases after stimulation. A one-way ANOVA on growth rates at different patterns and frequencies of stimulation $(n=73)$ showed a significant difference in growth rate after phasic stimulation or stimulation at $10 \mathrm{~Hz}$, compared to lower frequency or no stimulation (Fig. 7). This analysis represents the mean response of a population of growth cones to different stimulus patterns. Inspection of Table 2 shows that greater variability of response was associated with tonic stimulation at lower frequencies. Outgrowth of all 11 growth cones was inhibited by the phasic stimulus, but only half of those stimulated with the same number of impulses delivered in a tonic $2.5 \mathrm{~Hz}$ pattern were inhibited (The responses to these 2 types of stimuli were significantly different, $p<0.025$, using a chi-square comparison of the number of growing axons before and after phasic versus tonic stimulation at $2.5 \mathrm{~Hz}$.) Thus, to initiate roughly the same inhibition of growth rate seen following phasic stimulation, 4 times as many impulses had to be delivered at a constant frequency. Taken together, these results indicate that it is not merely the number of impulses delivered in a given time which is important in inhibiting neurite outgrowth, but that the pattern and frequency of the impulses are relevant.

Changes in morphology of the growth cone described following phasic stimulation were also observed immediately following tonic stimulation. Even at the lower frequency stimulation, where outgrowth persisted in some cases, retraction of the filopodia and lamellipodia was often initiated by the stimulus. In 2 instances stimulation at $2.5 \mathrm{~Hz}$ and $5 \mathrm{~Hz}$ caused a transient retraction and outgrowth resumed after $30 \mathrm{~min}$ of continuous stimulation.

\section{Accommodation}

Cultures stimulated with the phasic pattern in an incubator for approximately $24 \mathrm{hr}$ were found to contain numerous actively growing neurites (Fig. $8 A$ ) with normal-appearing growth cones (Fig. $8 B$ ) in the presence of this normally inhibitory stimulus. The number of lanes in the culture dish with neurites extending under the barrier was not significantly different on the stimulated or unstimulated sides after 24,48 , or $72 \mathrm{hr}$ of continuous phasic stimulation, and there was no significant difference in the number of DRG neurons in the stimulated or nonstimulated side compartments after $72 \mathrm{hr}$ of continuous stimulation.

These electrically conditioned cultures were placed on the microscope stage and the rate of outgrowth of neurites that apparently had normal growth cones was monitored while the phasic stimulus was maintained. Figure $8 C$ illustrates that the growth rate of these conditioned growth cones was normal even in the presence of continuous phasic stimulation. Outgrowth of these conditioned neurites was not halted by switching the stimulus off or on again within the intervals tested (Fig. $8 A$ and Fig. 


\section{Stim. Off}

\section{$-51 \mathrm{~min}$}

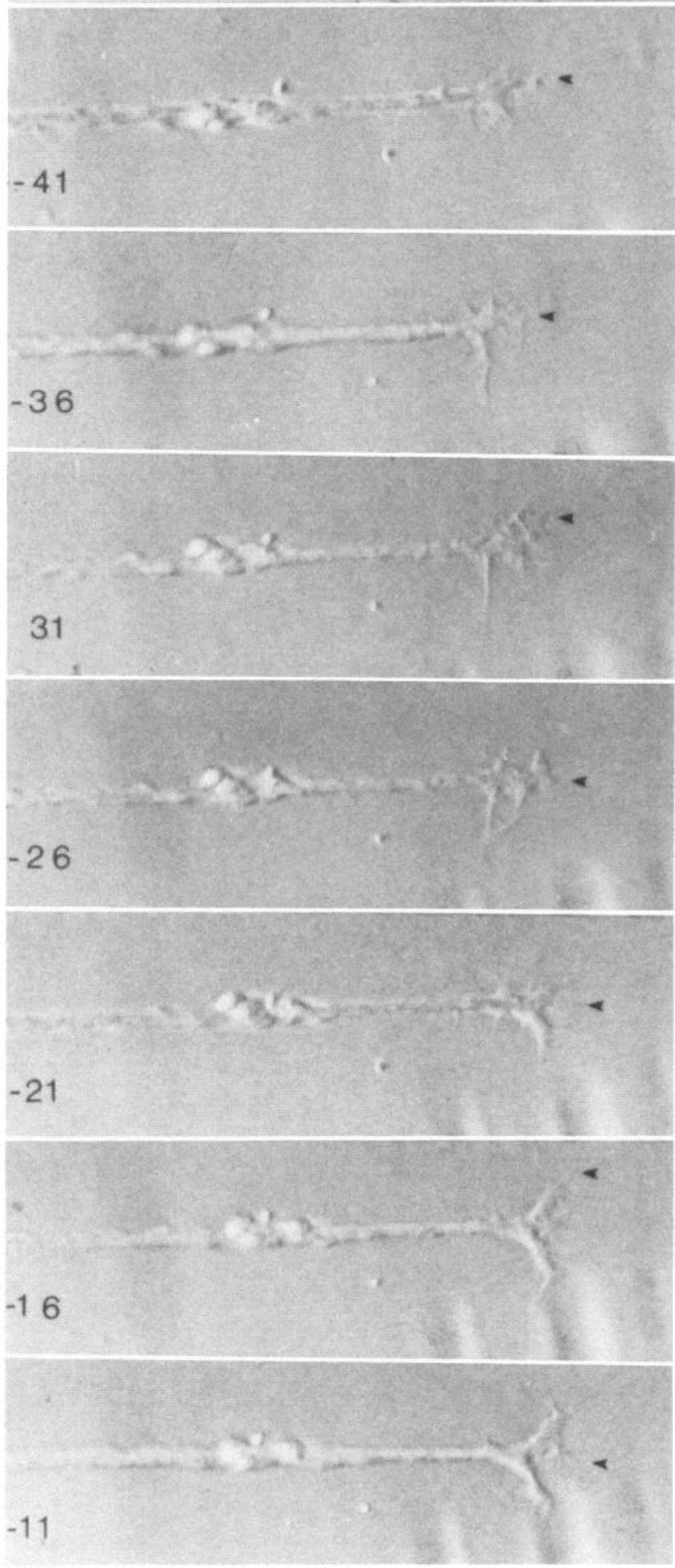

$-6$

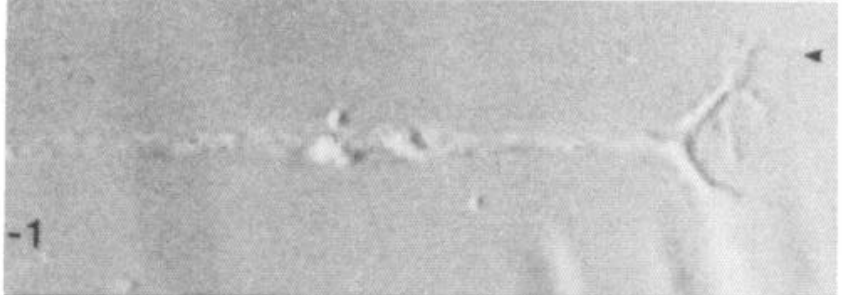

\section{Stim. On}

$+3$
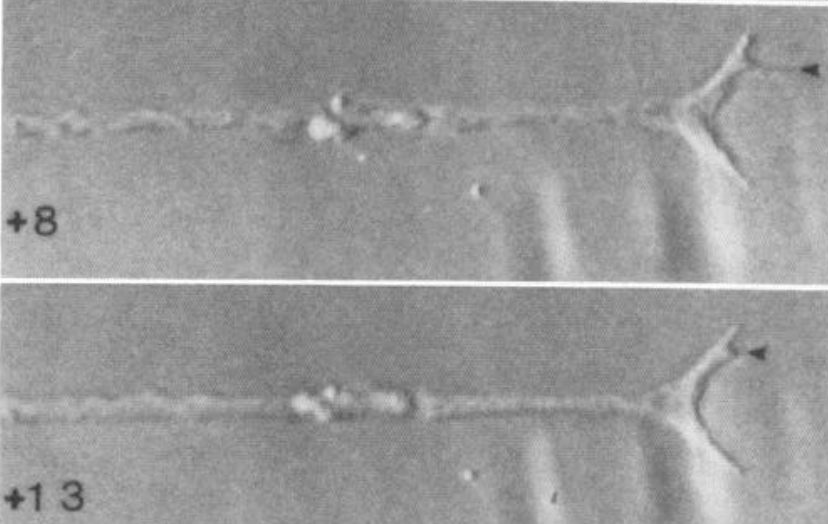

$+13$
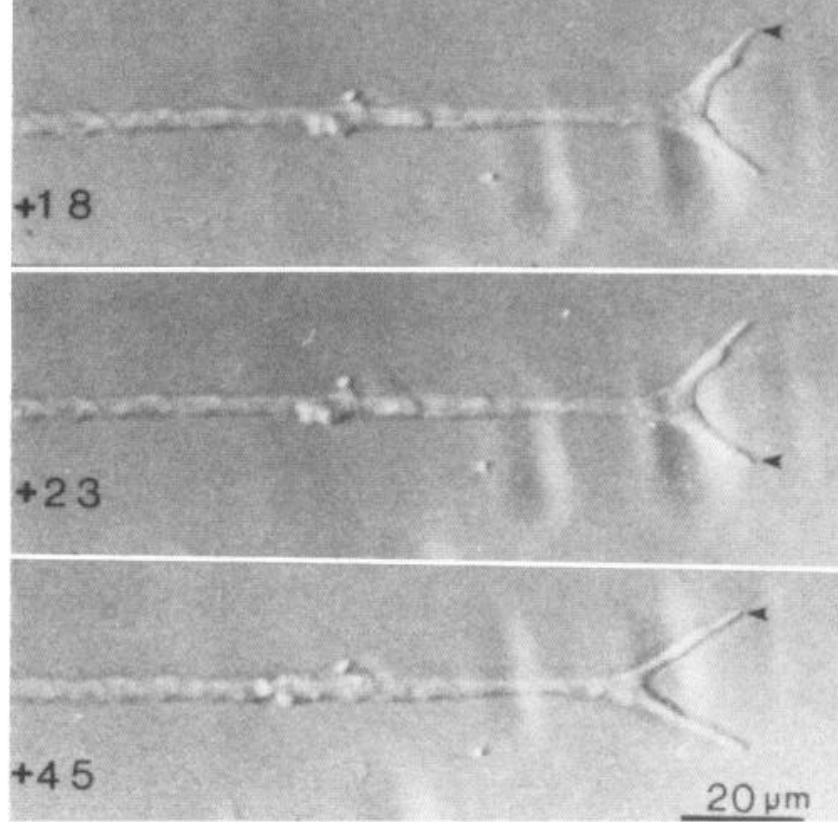
Table 1. Effect of electrical stimulation on neurite outgrowth: phasic pattern of electrical stimulation

\begin{tabular}{|c|c|c|c|c|c|}
\hline Stimulus condition & $\begin{array}{l}\text { Prestimulus } \\
\text { growth rate } \\
(\mu \mathrm{m} / \mathrm{min})\end{array}$ & Corr. $r$ & $\begin{array}{l}\text { Poststimulus } \\
\text { growth rate } \\
(\mu \mathrm{m} / \mathrm{min})\end{array}$ & Corr. $r$ & $\begin{array}{l}\text { Difference } \\
\text { in rates }\end{array}$ \\
\hline Phasic & +0.54 & +0.976 & -0.064 & -0.807 & -0.60 \\
\hline Phasic & +0.14 & +0.401 & -0.034 & -0.294 & -0.17 \\
\hline Phasic & +0.17 & +0.641 & -3.02 & -0.838 & -3.2 \\
\hline Phasic & +0.35 & +0.924 & -0.33 & -0.764 & -0.68 \\
\hline Phasic & +0.17 & +0.918 & -0.19 & -0.859 & -0.36 \\
\hline Phasic & +0.067 & +0.883 & -0.052 & -0.755 & -0.12 \\
\hline Phasic & +0.75 & +0.991 & -0.022 & -0.279 & -0.77 \\
\hline Phasic & +0.14 & +0.469 & -0.24 & -0.968 & -0.38 \\
\hline Phasic $^{a}$ & +0.34 & +0.959 & -0.27 & -0.987 & -0.61 \\
\hline Phasic $^{b}$ & +0.24 & +0.822 & -0.41 & -0.938 & -0.65 \\
\hline Phasic $^{b}$ & +0.34 & +0.647 & -0.15 & -0.506 & -0.49 \\
\hline Mean & +0.29 & & -0.43 & & $-0.73 p<0.01$ \\
\hline SD & +0.202 & & +0.867 & & +0.842 \\
\hline Phasic + TTX $(1 \mu \mathrm{M})$ & +0.39 & +0.977 & +0.70 & +0.931 & +0.31 \\
\hline Phasic + TTX $(1 \mu \mathrm{M})$ & 0.00 & 0.000 & +0.81 & +0.942 & +0.81 \\
\hline Phasic + TTX $(1 \mu \mathrm{M})$ & +0.59 & +0.962 & +0.54 & +0.930 & -0.050 \\
\hline Phasic + TTX $(1 \mu \mathrm{M})$ & +0.18 & +0.980 & +0.51 & +0.933 & +0.33 \\
\hline Mean & +0.29 & & +0.64 & & +0.35 n.s. \\
\hline $\mathrm{SD}$ & +0.256 & & +0.141 & & +0.353 \\
\hline Control & +0.21 & +0.768 & & & \\
\hline Control & +0.45 & +0.952 & & & \\
\hline Control & +0.75 & +0.841 & & & \\
\hline Control & +0.15 & +0.985 & & & \\
\hline Control & +0.69 & +0.959 & & & \\
\hline Control & +0.31 & +0.952 & & & \\
\hline Control $^{a}$ & +0.16 & +0.995 & & & \\
\hline Control & +0.33 & +0.959 & & & \\
\hline Control & +0.34 & +0.998 & & & \\
\hline Mean & +0.38 & & & & \\
\hline $\mathrm{SD}$ & 0.217 & & & & \\
\hline
\end{tabular}

${ }^{a}$ In $10 \mathrm{~mm}$ HEPES buffered balanced salt solution, without horse serum, in room atmosphere.

"Cultured on glass coated with collagen and polylysine.

Growth rates are measured as the linear regression of distance $(\mu m)$ grown over time in minutes. Statistics are paired $t$-tests.

$9, A, B)$. No consistent change in morphology of the growth cone or rate of outgrowth (Table 3 ) was associated with the change in stimulus conditions in electrically conditioned growth cones (Fig. 9C). Intracellular recordings verified that action potentials were being activated in these conditioned DRG neurons in response to the phasic stimulus (Fig. $8 D$ ). Stimulating the control side of the same dishes with the same extracellular electrodes caused the unconditioned growth cones to collapse.

\section{Discussion}

Electrical activity provided by phasic stimulation initiates rapid structural changes in the growth cone of rat DRG neurons in culture, and it inhibits growth cone motility, stopping neurite outgrowth within minutes. Withdrawal of the growth cone is typically followed by retraction of the neurite for several mi- crons. Recovery did not ensue within $1-4 \mathrm{hr}$ after termination of the stimulus, but in view of uncertainties associated with maintaining cultures on the microscope stage for prolonged periods and the apparent accommodation of chronically conditioned growth cones, further experiments on this question are warranted. The dynamics of the recovery processes were not explored systematically. A conditioning period of $24 \mathrm{hr}$ was chosen for pragmatic reasons, and because the phenomenon was fully expressed by the end of this treatment period.

The morphological changes initiated by phasic stimulation include an immediate retraction of filopodia and withdrawal of the lamellipodium into the nerve terminal, leaving a blunted or pointed neurite ending. Both the actin cytoskeleton of the growth cone and the growth cone membrane show these pronounced morphological changes within $15 \mathrm{~min}$ of phasic stimulation.

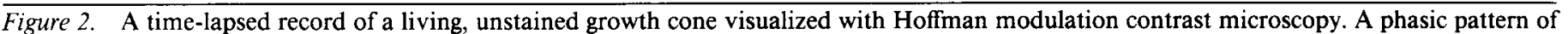

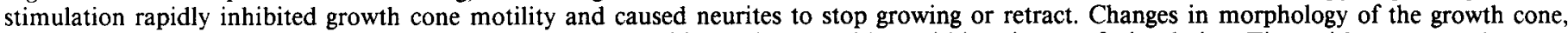

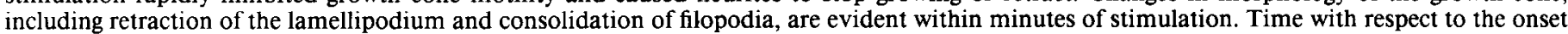
of stimulation is indicated in minutes. 
Inhibition of Neurite Growth by Electric Stimulation
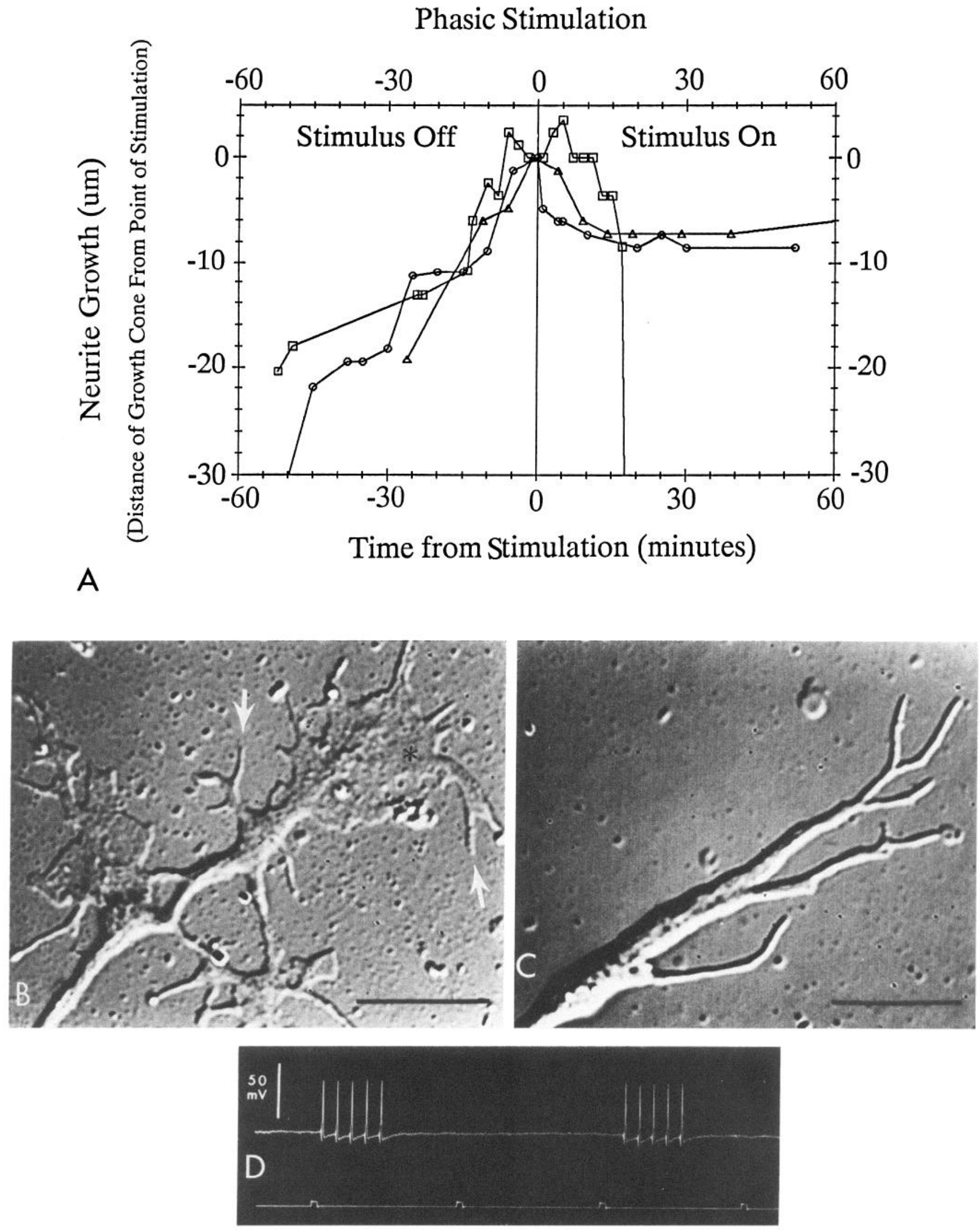


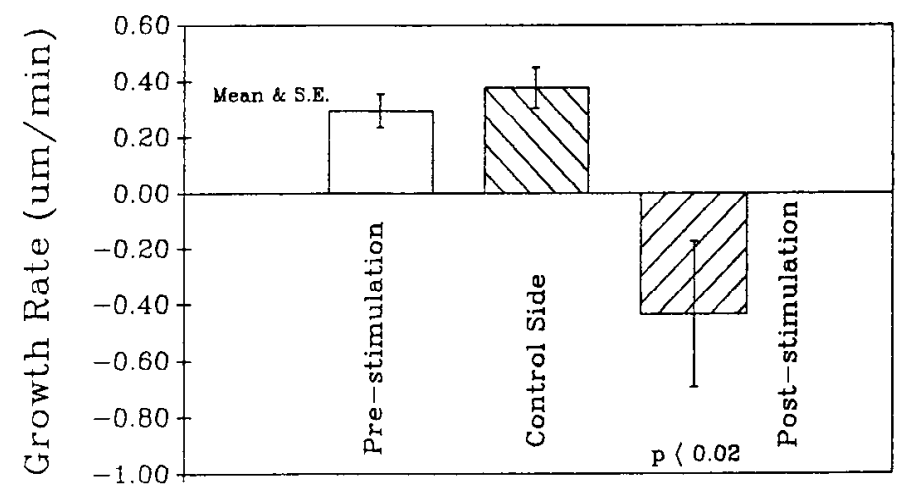

Figure 4. Mean growth rates were similar before stimulation compared to controls (neurites from the barrier opposite the one stimulated) (n.s., $t$-test; $n=11$ and 9 growth cones). The negative mean growth rate following stimulation, which is statistically significant from the rate before stimulation $(p<0.02)$, indicates retraction of the neurites $(n=$ $11 ; p<0.003$, one-way ANOVA).

Experiments in the presence of TTX and with stimulation at different patterns and frequencies show that the response depends on activation of voltage-dependent sodium channels at a critical frequency. This important control was not possible in experiments on Heliosoma neurons because they are insensitive to TTX (Cohan and Kater, 1986). Tonic stimulation at $10 \mathrm{~Hz}$ was more effective in inhibiting neurite outgrowth than stimulation at 5 or $2.5 \mathrm{~Hz}$, but bursting stimulation rapidly inhibited neurite outgrowth in all growth cones investigated. It has been suggested that calcium influx through voltage-gated channels could initiate cytoskeletal changes that would affect the outgrowth of neurites (Cohan and Kater, 1986). Bursting and higherfrequency stimulation may causc grcater calcium influx by slowing the recovery of normal membrane potential, which could increase the duration of the action potential or cause a greater imbalance in processes maintaining the internal calcium homeostasis. This suggests that the inhibitory effects of electrical activity would depend on the particular pattern of spontaneous activity arising in developing neural circuits, and on individual differences in growth cone structure or physiological condition (as is evident from the variable responses shown in Fig. 6 and Table 2). According to this view, electrical activity should not be regarded simply as a "stop signal" for neurite outgrowth, but as an added dimension of richly complex coordination between developing neural circuit activity and the emerging structure of interconnecting neurons. The physiological effects of electrical activity would interact with those impelled by many other factors (neurotransmitters, substrate specificity, trophic influences) to orchestrate development of the nervous system with a specificity and resiliency not attainable through genetic instruction alone.

The evidence that stimulation can increase calcium influx is compelling, and there are many possible effects of increased intracellular free calcium on the axonal cytoskeleton. Action

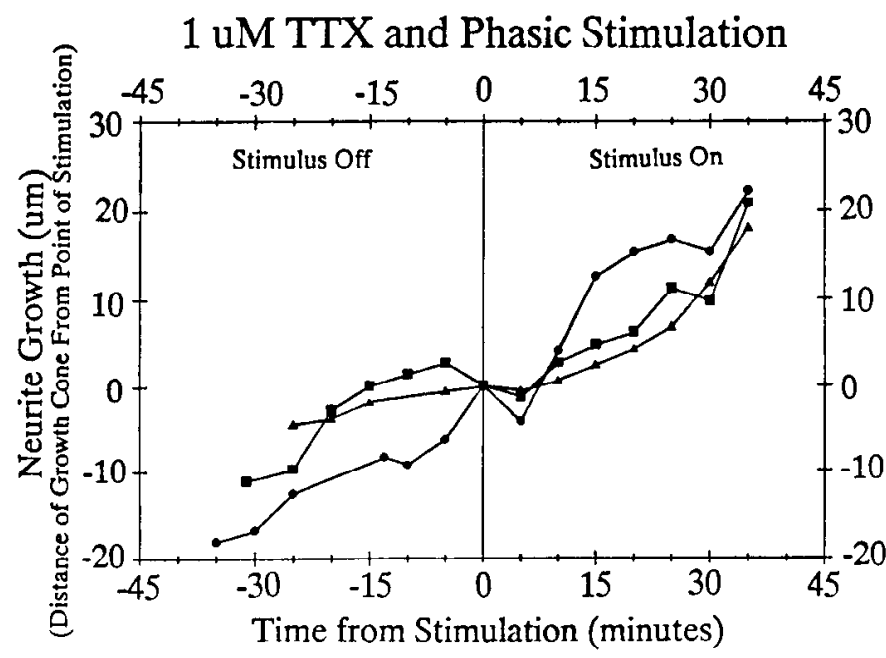

Figure 5. Neurite outgrowth continues in the presence of $1 \mu \mathrm{M}$ TTX and phasic stimulation, indicating that the stimulation-induced inhibition of neurite outgrowth requires activation of sodium channels.

potentials are accompanied by increased calcium conductance in many different types of neurons (cf. Hagiwara and Byerly, 1981; Kaczmarek and Strumwasser, 1981; Hagiwara, 1983; Reuter, 1983; Tsien, 1983; Strong, 1984; Strong and Kac7marek, 1986), and calcium conductances have been detected in the growth cone membrane (Anglister et al., 1982; Bolsover and Spector, 1986) together with other voltage-sensitive ion channels (Grinvald and Farber, 1981; Freeman et al., 1985; MacVicar and Llinas, 1985; Belardetti et al., 1986). Many biochemical reactions essential for growth cone motility and neurite outgrowth are sensitive to internal calcium concentration, which is normally very low in DRG neurons, as in other nerve cells (ca. $10^{-7} \mathrm{M}$ ) (Miller, 1987). An increase in calcium ion concentration in growth cones might alter the rate of microtubule assembly or disassembly (Schliwa et al., 1981), which is a major component of the neurite cytoskeleton and is essential for axoplasmic transport. An inhibitory action of stimulation on axoplasmic transport would be consistent with the regression of axoplasm observed in the terminal segments of axons in response to stimulation. Increased intracellular calcium in the growth cone could also cause a reorganization of the actin microfilaments [Adelstein and Eisenberg, 1980; Bernstein and Ramburg, 1985; Smith, 1988 (review)]. Effects on actin are suggested by the rapid retraction of filopodia following stimulation, as the core of filopodia is formed of filamentous bundles of actin (Letourneau, $1983,1985)$. Interactions with other components of the cytoskeleton through calcium-dependent or calcium/calmodulin-dependent mechanisms (Purich et al., 1981; Yamamoto et al., 1983; Vallano et al., 1985; Bramberg et al., 1986) or calciumdependent modifications in the axoplasmic fluidity (Llinas, 1979) could also influence growth cone motility in association with increased calcium conductance during action potentials.

\footnotetext{
Figure 3. A, A phasic pattern of electrical stimulation stops neurite outgrowth and often initiates retraction of the nerve terminal. Cessation of neurite outgrowth is accompanied by withdrawal of the growth cone into the axon terminal (compare $B$ and $C$ ). $B$, Growth cones from axons extending under the barrier from the unstimulated side exhibit broad lamellipodia $\left({ }^{*}\right)$ with numerous filopodia (arrows). $C$, In the same culture dish, axons from the side that had been stimulated for $15 \mathrm{~min}$ terminate in slender endings that lack growth cones. (Refer to Fig. $1 C$ for microscopic technique.) $D$. Intracellular recordings from DRG neurons in the side chamber confirm that the phasic stimulation applied across the barrier excites action potentials in axons that traverse the barrier. Time in seconds is indicated on the lower trace. Scale bars, $10 \mu \mathrm{m}$.
} 


\begin{tabular}{|c|c|c|c|c|c|}
\hline $\begin{array}{l}\text { Stimulus } \\
\text { condition } \\
\text { (tonic) }\end{array}$ & $\begin{array}{l}\text { Prestimulus } \\
\text { growth rate } \\
(\mu \mathrm{m} / \mathrm{min})\end{array}$ & Corr. $r$ & $\begin{array}{l}\text { Poststimulus } \\
\text { growth rate } \\
(\mu \mathrm{m} / \mathrm{min})\end{array}$ & Corr. $r$ & $\begin{array}{l}\text { Difference } \\
\text { in rates }\end{array}$ \\
\hline $10 / \mathrm{sec}$ & +0.55 & +0.874 & -2.5 & -0.543 & -3.0 \\
\hline $10 / \mathrm{sec}$ & +0.32 & +0.805 & -0.54 & -0.915 & -0.86 \\
\hline $10 / \sec$ & +0.60 & +0.982 & -0.10 & -0.642 & -0.70 \\
\hline $10 / \mathrm{sec}$ & +0.48 & +0.993 & +0.58 & +0.995 & +0.10 \\
\hline Mean & +0.49 & & -0.64 & & -1.13 \\
\hline $\mathrm{SD}$ & 0.122 & & 1.32 & & 1.35 \\
\hline $5 / \mathrm{sec}$ & +0.25 & +0.927 & +0.093 & +0.541 & -0.16 \\
\hline $5 / \mathrm{sec}$ & +0.080 & +0.835 & +0.17 & +0.394 & -0.090 \\
\hline $5 / \mathrm{sec}$ & +0.31 & +0.971 & -0.10 & -0.965 & -0.41 \\
\hline Mean & +0.21 & & +0.054 & & -0.159 \\
\hline $\mathrm{SD}$ & 0.119 & & 0.139 & & +0.250 \\
\hline $2.5 / \mathrm{sec}$ & +0.64 & +0.975 & -0.92 & -0.787 & -1.56 \\
\hline $2.5 / \mathrm{sec}$ & +0.12 & +0.730 & +0.31 & +0.901 & +0.19 \\
\hline $2.5 / \mathrm{sec}$ & -0.36 & -0.320 & -0.87 & -0.901 & -0.51 \\
\hline $2.5 / \mathrm{sec}$ & +0.91 & +0.989 & +1.68 & +0.957 & 10.77 \\
\hline $2.5 / \mathrm{sec}$ & +0.73 & +0.991 & +0.79 & +0.924 & +0.060 \\
\hline $2.5 / \mathrm{sec}$ & +0.69 & +0.984 & +1.2 & +0.968 & +0.51 \\
\hline $2.5 / \mathrm{sec}$ & +0.13 & +0.899 & -0.99 & -0.980 & -1.12 \\
\hline $2.5 / \mathrm{sec}$ & +0.14 & +0.841 & -0.77 & -0.995 & -0.91 \\
\hline $2.5 / \mathrm{sec}$ & +0.91 & +0.989 & +1.7 & +0.957 & +0.79 \\
\hline Mean & +0.43 & & +0.24 & & -0.198 n.s. ${ }^{a}$ \\
\hline SD & 0.441 & & +1.15 & & +0.862 \\
\hline
\end{tabular}

a Paired $t$-test

Although the mechanisms by which calcium may interact with the cytoskeleton of the growth cone and axonal terminal are not fully understood, there is no question of the importance of intracellular calcium in regulating growth cone motility in many different types of neurons and in nonncuronal cells (Bray, 1973; Llinas, 1979; Gunderson and Barrett, 1980; Anglister et al., 1982; Kostenko et al., 1983; Bixby and Spitzer, 1984; Connor, 1986; Cohan et al., 1987). In cultured mammalian neurons, intracellular free calcium concentration is elevated in neurons that are actively extending neurites compared to quiescent neurons, and within active neurites, the concentration of calcium is higher in the growth cone than in the proximal neurites or soma (Connor, 1986). In the same study, motility was observed only in neurons with calcium levels within a range of about 100$300 \mathrm{~nm}$, and different types of treatments applied to change the internal calcium concentration above or below this range inhibited neurite outgrowth (Cohan et al., 1987). Pharmacological manipulations that increase intracellular calcium in Heliosoma neurons in culture, such as the calcium ionophore A23187, suppress elongation and motility of filopodia and lamellipodia, and high concentrations of inorganic calcium channel blockers $\left(\mathrm{La}^{3+}, \mathrm{Cd}^{2+}, \mathrm{Co}^{2+}\right)$ (Weiss, 1974; Hagiwara and Byerly, 1981) also suppress elongation and growth cone movements, presumably by reducing intracellular free calcium below critical levels (Cohan et al., 1987; Mattson and Kater, 1987). Neurite outgrowth can also be suppressed from Heliosoma neurons in culture by certain neurotransmitters, which also cause a measurable increase in intraneuronal calcium levels (Haydon et al., 1984; Cohan and Kater, 1986; Cohan et al., 1987; McCobb et al., 1988). Recent experiments with Heliosoma neurons using fura-2 to measure intracellular calcium show definitively that electrical stimulation is accompanied by a sudden increase in intracellular calcium, which returns to normal levels rapidly after stimulation is stopped (Cohan et al., 1987). In rat DRG neurons, similar calcium localization methods show that depolarization induced by clevated cxtcrnal potassium causes a rapid increase in internal calcium, which is elevated for $30 \mathrm{~min}$ or more (Thayer et al., 1988).

In contrast to Heliosoma neurons, where growth cone motility is inhibited during the period of electrical stimulation but recovers rapidly after stimulation is stopped, growth cones of mouse DRG neurons did not recover motility soon after the stimulus ceased, and in many cases the neurite was resorbed into the nearest branch point. This difference in response between these snail neurons and mammalian sensory neurons may reflect an inability of DRG neurons to recover from increased intracellular calcium following substantial depolarization. Alternatively, more extensive cytoskeletal collapse may follow elevated $\left[\mathrm{Ca}^{2+}\right]_{i}$ in the smaller delicate growth cones and axon terminals of mammalian DRG neurons. Microfluorimetric measurements of intracellular calcium concentration using fura-2 indicate that calcium transients in rat DRG ncurons, induced by potassium depolarization, are buffered extraordinarily slowly (Thayer et al., 1988). A slow rate of calcium buffering in DRG neurons has also been suggested by Jia and Nelson (1986) to account for the pronounced synaptic rundown following repetitive stimulation in high external calcium, which is characteristic of synapses from DRG neurons. Intracellular free calcium measurements (Thayer et al., 1988) show that following potassiuminduced depolarization, the intracellular calcium concentration increases rapidly from normal values below $100 \mathrm{~nm}$ to over 500 $\mathrm{nM}$ in the cell body, but after repolarizing the cells, the concen- 


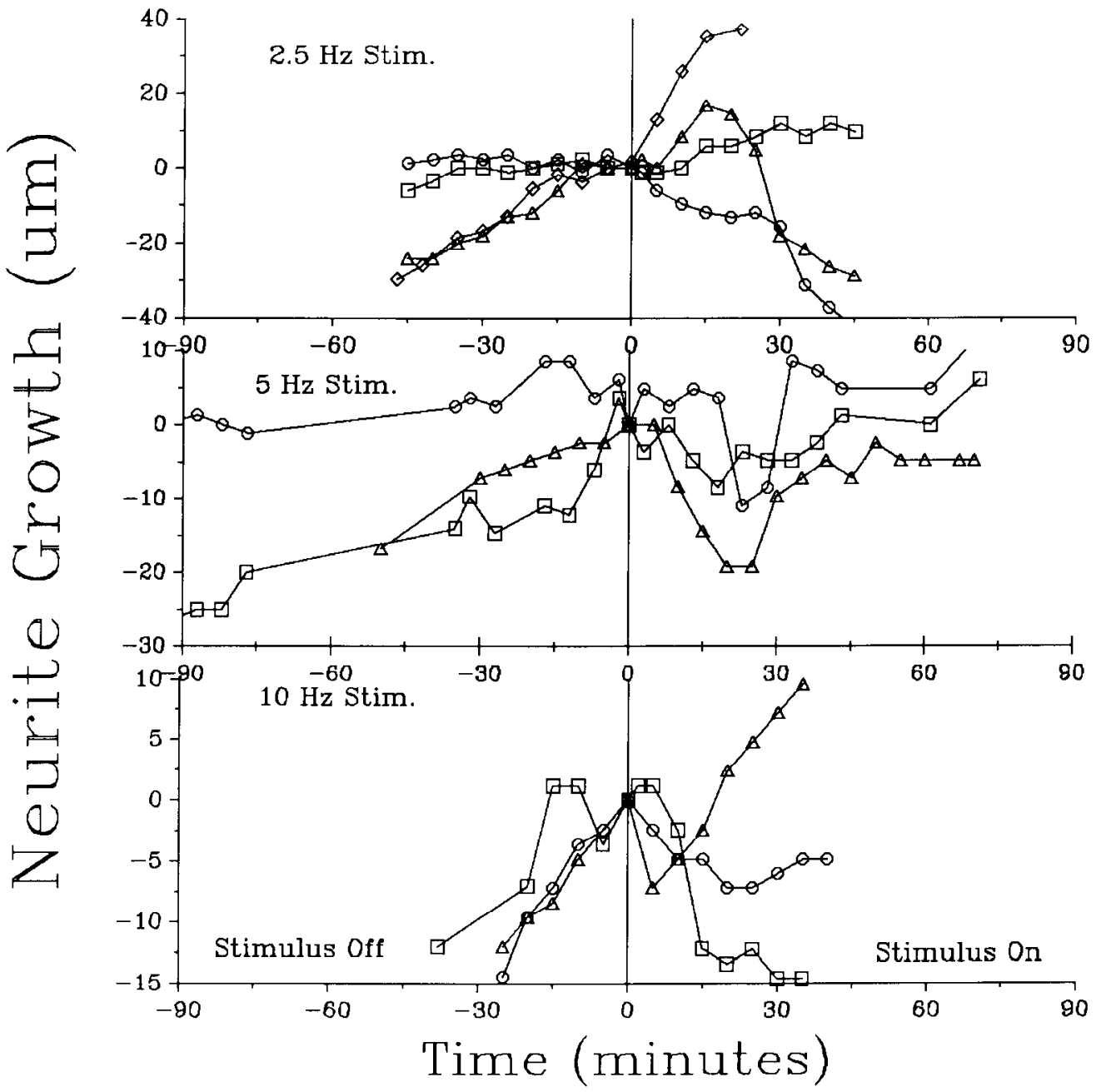

Figure 6. Growth rates of selected growth cones, illustrating the variation in response following constant frequency (tonic) stimulation at different frequencies. Inhibition of outgrowth or retraction usually followed tonic stimulation; however, in some instances outgrowth was not inhibited by the tonic stimulus, and in other cases growth resumed after a period of inhibition. All growth cones showed morphological changes, including retraction of the filopodia and lamellipodium within 5 min of stimulation. Variation decreased with the higher-frequency stimulation (cf. Fig. 7). These variable responses contrast with the inhibitory response following a phasic stimulus delivering the same number of action potentials as the $2.5 \mathrm{~Hz}$ tonic stimulus (cf. Fig. $3 A$ ). tration of intracellular calcium remains elevated. Internal calcium concentration then returns to normal levels very slowly (in about $30 \mathrm{~min}$ ) compared to other types of neurons. Similar responses were measured in neuronal processes, although calcium transients were less extreme there than in the cell soma, which suggests a somewhat better calcium homeostasis or lesser calcium influx in the neurites. Responses might differ to electrically evoked depolarization, however. This question could be investigated in this tissue culture system using fura- 2 imaging. Thus, the persistent block of growth-cone motility in DRG neurons may derive from a sustained elevation of intracellular calcium, which could have persistent effects on the integrity of the cytoskeleton and encumber other calcium-sensitive mechanisms necessary for neurite outgrowth. Resorption of neurites may be a catastrophic result of this calcium imbalance in the extreme.

The insensitivity of DRG neuron growth cones to long-term stimulation suggests somc accommodating process related to calcium influx, efflux, or buffering, enabling continued outgrowth during action potential activity. This accommodation may be achieved by reducing the calcium conductance in the neurite membrane, or by increasing the calcium-buffering capacity in neurites of electrically active neurons. The calcium-buffering capacity could include mechanisms that regulate internal calcium stores or the rates of transmembrane cationic exchange processes. Modulation of calcium homeostatic physiology by patterned electrical activity could have a significant impact on development, by interacting with other factors that control cell death, neurite outgrowth, and synaptogenesis through changes in intracellular calcium.

The period of time required for this accommodation (hours) allows the possibility of compensatory responses requiring synthesis and transport of proteins, membrane channels, ion pumps, or organelles involved in maintaining calcium homeostasis at the nerve terminal in the presence of electrical activity. Internal calcium ion concentration of neuronal processes is regulated in part by mitochondria and other vesicular organelles, such as the smooth endoplasmic reticulum (cf. Andrews et al., 1987). Translocation of calcium-buffering organelles into the growth cone could be a possible mechanism for increasing the intracellular calcium-buffering capacity of electrically conditioned growth cones, which are resistant to the inhibitory effects of stimulation. The movement of organelles along microtubules is influenced by calcium ions and second-messenger regulation [ $\Lambda$ llen et al., 1985; Koonce and Schliwa, 1985; Bridgman et al., 1986; Schnapp and Reese, 1986 (review)]. Changes in distribution and transport of organelles into growth cones of Aplysia bag cell neurons have been described following treatments that elevate intracellular cAMP (Forscher et al., 1987). By affecting the organelle-microtubule interactions, calcium may increase the probability of transient organelle associations with microtubules or the microtubules themselves may be less linearly organized in the 


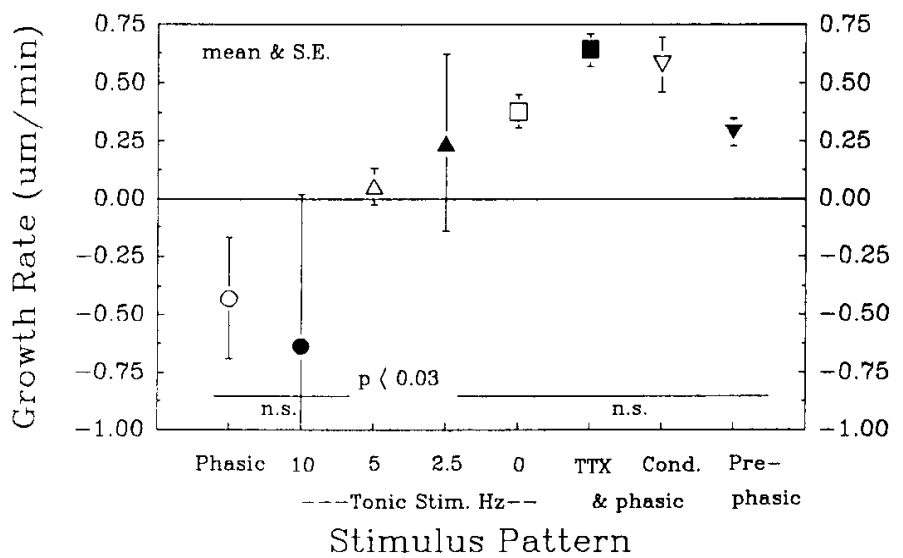

Figure 7. Activity-induced inhibition of neurite outgrowth depends on the pattern and frequency of stimulation (i.e., there are significant differences in growth rate among the 8 different patterns of stimulation tested; $p<0.008$ ). Outgrowth was less inhibited at the lower frequencies, although some contraction of the lamellipodium and withdrawal of filopodia was usually apparent. Mean growth rates following phasic stimulation, or tonic stimulation at $10 \mathrm{~Hz}$ were significantly slower $(p$ $<0.03$ ) than tonic stimulation at $2.5 \mathrm{~Hz}$, or the following controls: (1) growth rates before phasic stimulation (prephasic), (2) axons growing from the side opposite the one stimulated $(0 \mathrm{~Hz}),(3)$ phasic stimulation in the presence of $1 \mu \mathrm{M}$ TTX (TTX and phasic), or (4) after continuous phasic stimulation for $24 \mathrm{hr}$ (cond. and phasic). Growth rates for all categories before stimulation were not significantly different by an ANOVA $($ mean $=+0.36, \mathrm{SE}=0.0428, n=40$ ).

presence of calcium (Forscher et al., 1987). Such a process, which increases the calcium-buffering capacity, could help stabilize growth cones in electrically active neurons or make axon terminals that have formed synapses resistant to stimulus-evoked increases in $\left[\mathrm{Ca}^{2+}\right]_{\mathrm{i}}$.

Alternatives to the interpretation that accommodation restores normal free internal calcium levels cannot be ruled out by the experiments reported here. Other possibilities are that the accommodation may involve compensation in the reactions maintaining the integrity of the cytoskeleton and motility of the growth cone in the presence of elevated intracellular calcium concentration, or that the conditioning stimulus may have selected for growth cones that are not inhibited by electrical activity. This seems unlikely because no neurites were insensitive to an acute phasic stimulus. Moreover, the 2 instances of recovery in the presence of continuous low-frequency tonic stimulation (Fig. 6 and Table 2) support the feasibility of the accommodation hypothesis. However, not all neurites in these cultures are actively growing at any given time, and many neurites terminated without a growth cone bearing a lamellipodium. The internal calcium level may differ in different neurites. Selecting for examination those actively growing neurites that had a well-developed lamellipodium or active filopodial extensions may have led to the selection of those with intracellular calcium levels within a concentration range conducive to growth cone motility, but which could be readily perturbed beyond this range by electrical activity. In contrast, axons inhibited by abnormally low $\left[\mathrm{Ca}^{2+}\right]_{\mathrm{i}}$ might be transformed into an actively growing state by stimulation that raises the $\left[\mathrm{Ca}^{2+}\right]_{i}$ to levels that are permissive to growth cone motility. Experiments are in progress to investigate these alternatives.

Cessation of neurite outgrowth by action potentials could help consolidate a functional circuit during development by stabilizing the outgrowth of neurites that form appropriate synaptic contacts and leading to the retraction of growth cones from collatcrals that have not formed appropriate contacts at the time the neuron becomes electrically active. The timing of events, such as cell migration, differentiation, growth, synaptogenesis, and so forth, is critical in establishing the ultimate structure of the nervous system. Even a transient inhibition of growth cone motility could have significant developmental consequences for dendritic arborization, the pattern of axonal terminals, and synaptogenesis. In the context of competition between neurons for

Table 3. Effect of electrical activity on neurite outgrowth in growth cones conditioned to electrical stimulation: phasic stimulus to conditioned growth cones

\begin{tabular}{|c|c|c|c|c|c|}
\hline $\begin{array}{l}\text { Stimulus ON } \\
\text { growth rate } \\
(\mu \mathrm{m} / \mathrm{min})\end{array}$ & Corr. $r$ & $\begin{array}{l}\text { Stimulus OFF } \\
\text { growth rate } \\
(\mu \mathrm{m} / \mathrm{min})\end{array}$ & Corr. $r$ & $\begin{array}{l}\text { Stimulus ON } \\
\text { growth rate } \\
(\mu \mathrm{m} / \mathrm{min})\end{array}$ & Corr. $r$ \\
\hline+0.43 & +0.943 & +0.52 & +0.948 & +0.44 & +0.813 \\
\hline+0.56 & +0.974 & +1.1 & +0.966 & +0.72 & +0.969 \\
\hline+0.12 & +0.939 & & & & \\
\hline+0.81 & +0.938 & +0.071 & +0.327 & & \\
\hline+0.28 & +0.694 & +0.71 & +0.974 & & \\
\hline$+1.6^{a}$ & +0.961 & & & & \\
\hline+0.15 & +0.892 & -0.029 & 0.000 & & \\
\hline+0.24 & +0.985 & 0.000 & 0.000 & & \\
\hline+0.61 & +0.922 & & & & \\
\hline+0.62 & +0.893 & & & & \\
\hline+0.78 & +0.993 & & & & \\
\hline+0.74 & +0.990 & & & & \\
\hline$+0.58=$ mean & & $+0.40=$ mean & & $+0.58=$ mean & \\
\hline$+0.403=\mathrm{SD}$ & & $+0.459=\mathrm{SD}$ & & $+0.198=\mathrm{SD}$ & \\
\hline
\end{tabular}

- $10 \mathrm{~mm}$ HEPES buffered balanced salt solution, without horse serum, in room atmosphere, at $37^{\circ} \mathrm{C}$. Growth rates are not significantly different (ANOVA).

Cultures were conditioned to stimulation by approximately $24 \mathrm{hr}$ exposure to a phasic pattern of electrical stimulation. Test stimulus was also phasic (see Methods). 

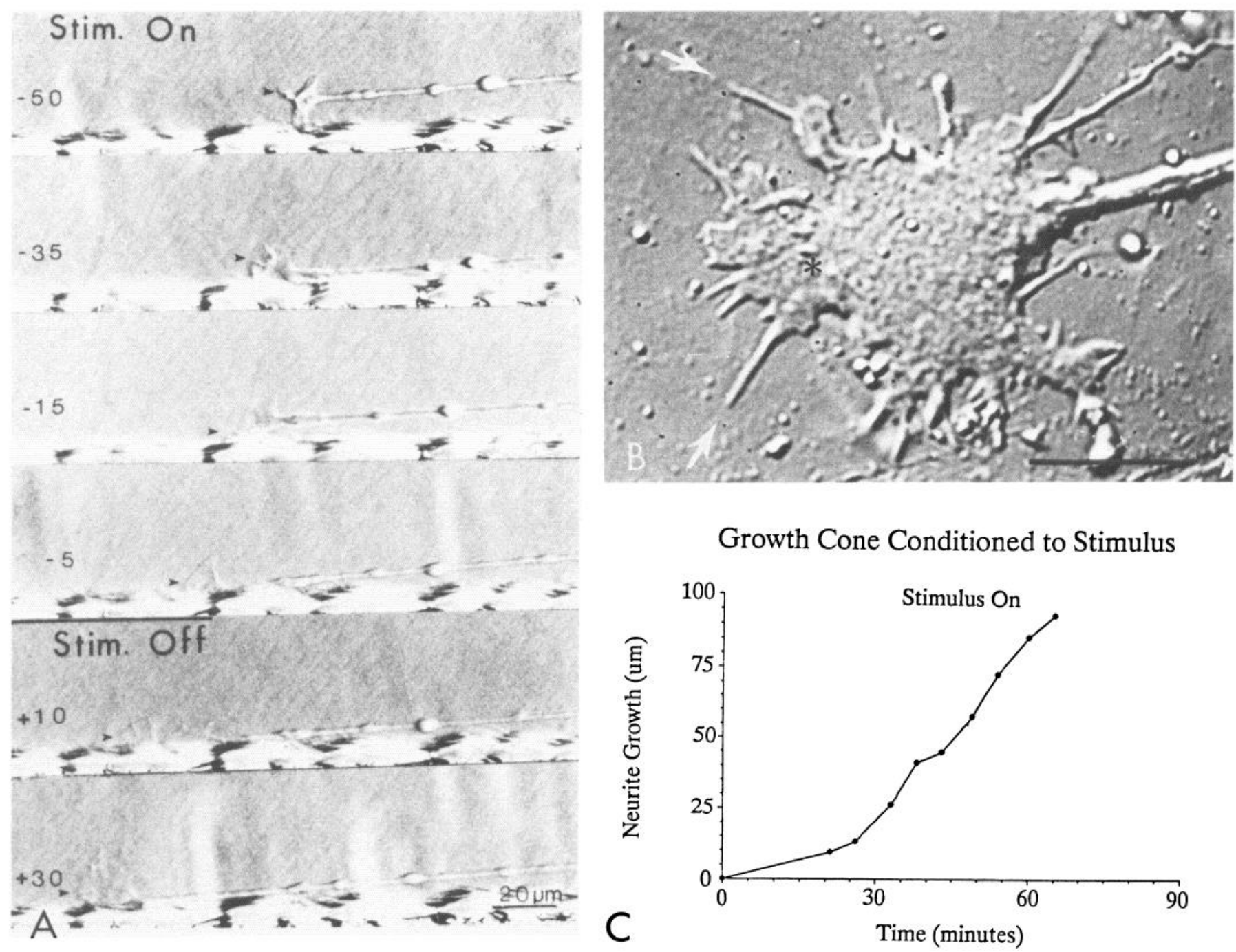

\section{Growth Cone Conditioned to Stimulus}
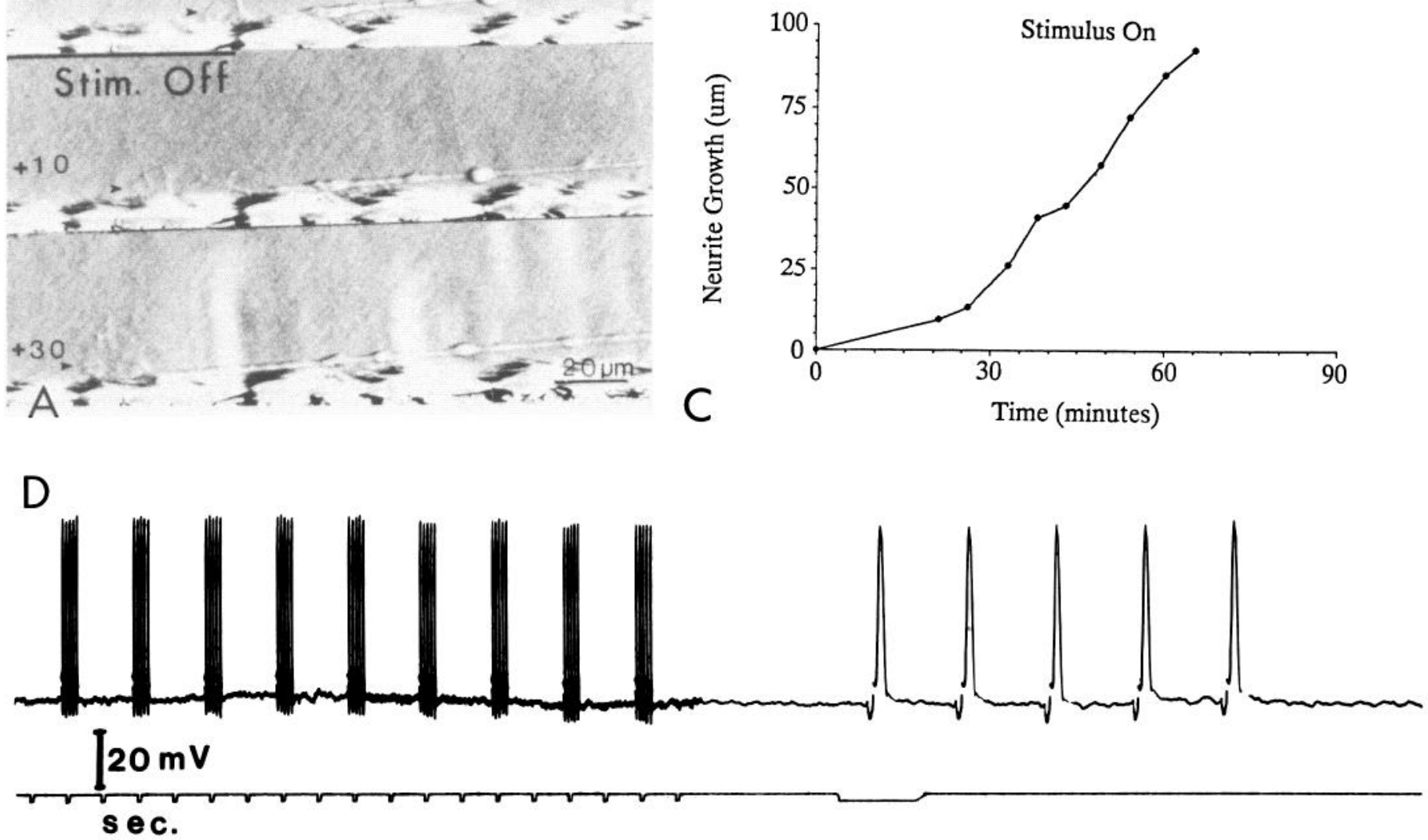

Figure 8. Phasic stimulation does not inhibit growth cone motility in neurons conditioned by chronic stimulation. Conditioned neurites were produced by stimulating cultures with the phasic stimulus for approximately $24 \mathrm{hr}$ inside an incubator. $B$, The morphology of growth cones in conditioned cultures was similar to normal (cf. Fig. 1C), both of which display a flattened lamellipodium (*) and numerous filopodia (arrow). (Microscopic technique as in Fig. 1C.) Scale bar, $10 \mu \mathrm{m}$. $A$, Time-lapsed recordings of growth cones from conditioned cultures demonstrate that in cultures conditioned by $24 \mathrm{hr}$ phasic stimulation, growth cone motility and neurite outgrowth $(C)$ continues during the phasic stimulation. This series of micrographs, made with Hoffman modulation contrast microscopy, shows a growth cone from a conditioned culture advancing along a scratch that delineates one of the lanes of the Campenot chamber. $D$, Intracellular recordings from DRG neurons confirm that action potentials are being evoked by the phasic stimulus after $24 \mathrm{hr}$ continuous stimulation.

postsynaptic sites, the consequences of a delayed rate of growth cone motility or the timing of transformation into a synapse would be particularly acute. Yet the process of accommodation would provide the possibility of neurite outgrowth in electrically active neurons, a capability that must be retained to allow growth and restructuring in the electrically active nervous system of postnatal animals. This process might also be important during regeneration. Scanning electron microscopy (Torigoe, 1988) and 


\section{Growth Cone Conditioned to Stimulus}

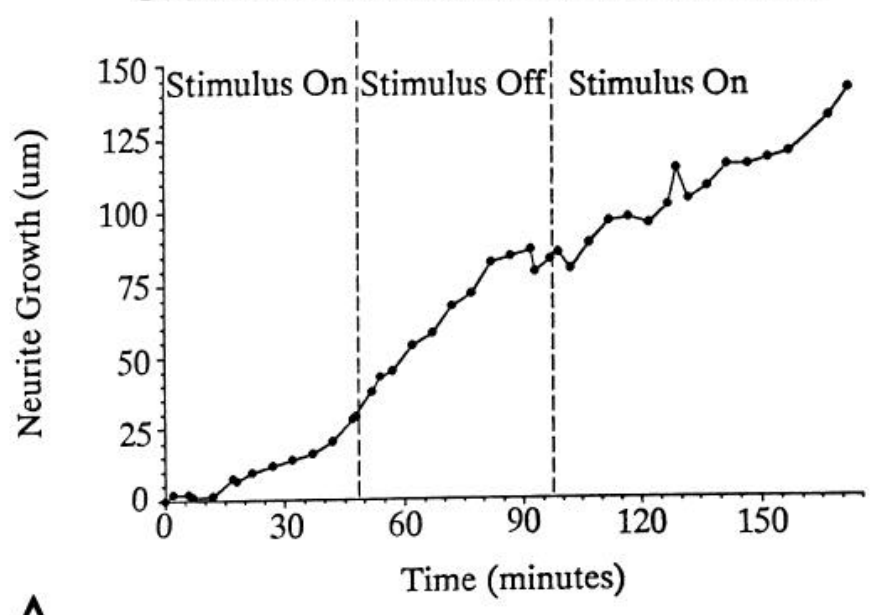

\section{Growth Cone Conditioned to Stimulus}

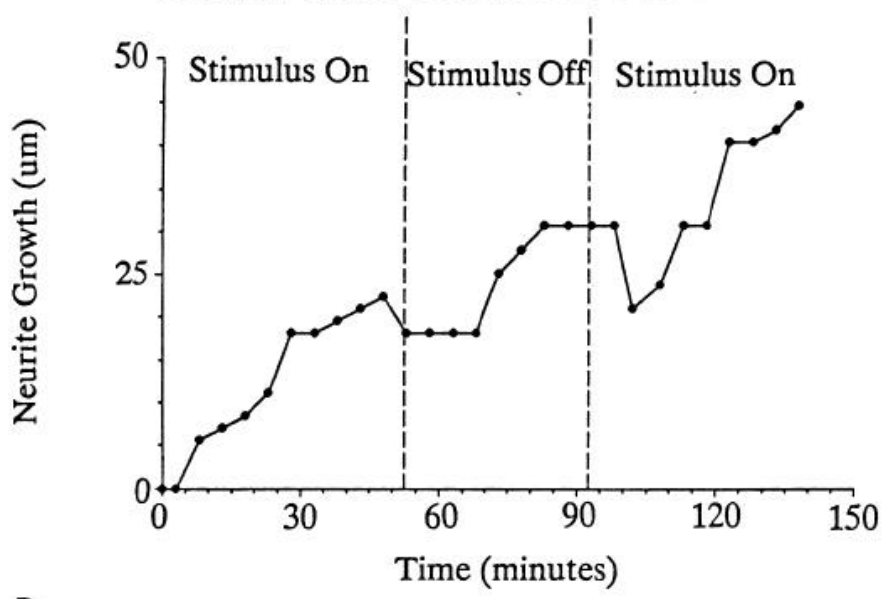

B

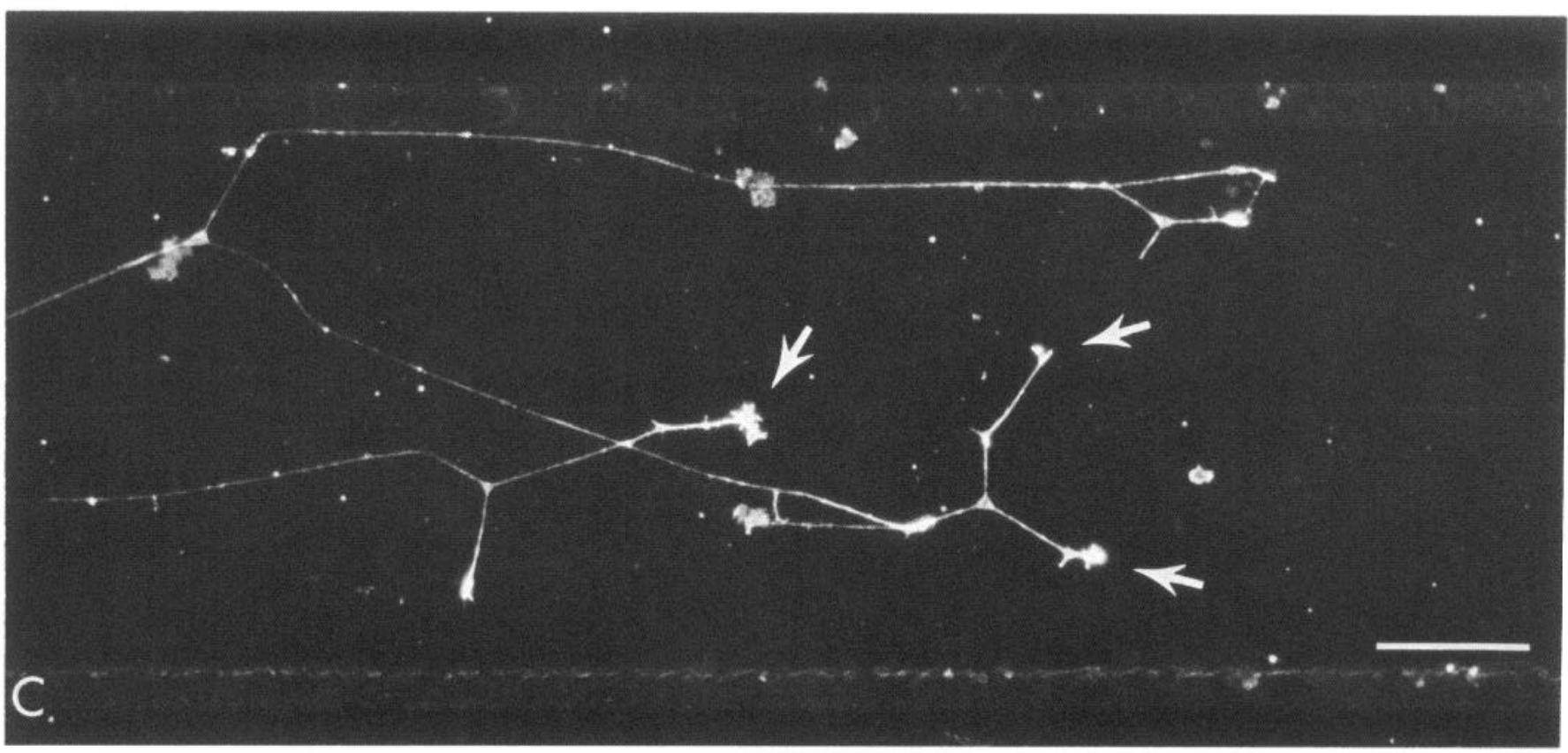

Figure 9. Outgrowth persists in cultures conditioned with chronic phasic stimulation, during periods when the stimulus is on or off. $A$ and $B$ plot the outgrowth of 2 growth cones from the preparation shown in $C$ during periods in which the phasic stimulation was on or off. After the timelapsed records were made, the culture was fixed and processed to localize filamentous actin using rhodaminated phalloidin. Even after several hours of experimentation, conditioned cultures contain numerous neurites with relatively normal growth cones that are resistant to the inhibitory effects of stimulation. Scale bar, $50 \mu \mathrm{m}$.

light level immunohistochemistry (Robbins and Polak, 1988) have revealed sprouting of growth cones from the neuromuscular junction of normal or denervated rat muscle, and inactivity is known to lead to preterminal sprouting from the frog neuromuscular junction (cf. Diaz and Pecot-Dechavassine, 1989). Activity-dependent suppression of growth cone motility might be one mechanism inhibiting such sprouting from functional synapses. In the event that activity is impaired, as a result of injury, for example, sprouting of growth cones from synapses would become permissible.

The results demonstrate that moderate electrical activity can have pronounced inhibitory effects on mammalian neurite outgrowth; however, the functional significance of activity-dependent inhibition of growth cone motility needs to be determined from experiments in vivo. The degree of inhibition of growth cone motility would depend on the frequency and pattern of spontaneous and evoked electrical activity arising during development and the dynamic aspects of calcium homeostasis in different growth cones or different types of neurons. It may be significant in this regard that DRG neurons show no spontaneous activity in dissociated cell culture. Also, the responses of growth cones to electrical activity might vary with other extracellular factors that regulate neurite attachment and outgrowth in vivo, which are not duplicated in culture preparations. Finally, electrical activity might have different effects on the motility of dendritic and axonal growth cones.

There is some controversy from in vivo studies on the importance of electrical activity in nervous system development. 
In many experiments significant alterations in synaptic architecture are produced by activity blockade (cf. Shatz, 1990), but in others no change is detectable (cf. reviews by Harris, 1981; Schmidt and Tieman, 1989). The results of this paper show that DRG growth cone motility and morphology are unaffected by TTX (Fig. 5), yet a direct action of electrical activity on growth cone motility was also documented.

The apparent accommodation to continuous stimulation helps explain how continued outgrowth of axons from electrically active neurons might be possible in vivo. In addition, this resolves the apparent paradox from our previous results in which an increase in synaptic number and strength developed in afferents exposed to long-term stimulation (Nelson et al., 1989). These new findings on the inhibitory effects of electrical activity on neurite outgrowth are contrary to the hypothesis that increased presynaptic activity alone is responsible for the increased number and strength of synapses from the stimulated convergent afferents, but suggest that postsynaptic factors must be incorporated into models of activity-dependent increase in synaptic efficacy seen in this preparation (Hebb, 1949; Stent, 1973). Finally, recognition that internal calcium levels and calcium homeostatic capacity may be dynamic, dependent on the pattern of electrical activity, and differing in different types of neurons may resolve the apparently contradictory results from different experiments on the role of internal calcium concentration in growth cone motility (e.g., Anglister et al., 1982; Kater et al., 1988; Campenot and Draker, 1989). Thus, accommodation to the inhibitory effects of electrical activity would enable further outgrowth, after a period of quiescence in growth cone motility, from neurons that enter a functional circuit during development. The consequences of this pause and the resumption of outgrowth could have a major developmental influence on the structure of developing neuronal circuits in the brain. Electrical activity appears to offer an important, functionally dependent mechanism of developmental control, in which the timing and pattern of electrical impulses, balanced against the dynamic calcium homeostatic capacity of growth cones, interact with other processes that also influence development through changes in intracellular calcium.

These results confirm and extend observations on the effect of electrical stimulation on neurite outgrowth reported initially in experiments with Heliosoma neurons (Cohan and Kater, 1986). This indicates that the mechanisms responsible for this inhibition are fundamental to neurite outgrowth in vertebrate and invertebrate neurons. By affecting the motility of growth cones, electrical activity in neural circuits could influence the pattern of connections formed during development. This may be one mechanism linking morphological and functional aspects of neural circuits in the developing CNS of mammals.

\section{References}

Adelstein RS, Eisenberg E (1980) Regulation and kinetics of the actinmyosin-ATP interaction. Annu Rev Biochem 49:921-956.

Allen RD, Weiss DG, Hayden JH, Brown DT, Fujiwake H, Simpson M (1985) Gliding movement of and bidirectional transport along single native microtubules from squid axoplasm: evidence for an active role of microtubules in cytoplasmic transport. J Cell Biol 100: $1736-1752$.

Andrews SB, Leapman RD, Landis DMD, Reese TS (1987) Distribution of calcium and potassium in presynaptic nerve terminals from cerebellar cortex. Proc Natl Acad Sci USA 84:1713-1717.

Anglister L, Farber I, Shahar A, Grinvald A (1982) Localization of voltage-sensitive calcium channels along developing neurites: their possible role in regulating neurite elongation. Dev Biol 94:351-365.
Belardetti F, Schacher S, Siegelbaum S (1986) Action potentials and single channel currents recorded from growth cones of Aplysia neurons in culture. J Physiol (Lond) 374:289-313.

Bernstein BW, Ramburg JR (1985) Reorganization of actin in depolarized synaptosomes. J Neurosci 5:2565-2569.

Bixby JL, Spitzer NC (1984) Early differentiation of vertebrate spinal neurons in the absence of voltage-dependent $\mathrm{Ca}^{2+}$ and $\mathrm{Na}^{+}$influx. Dev Biol 106:89-96.

Bolsover SR, Spector I (1986) Measurements of calcium transients in the soma, neurite, and growth cone of single cultured neurons. J Neurosci 6:1934-1940.

Bramberg JR, Bray D, Chapman K (1986) Assembly of microtubules at the tip of growing axons. Nature 321:788-790.

Bray D (1973) Model for membrane movements in the neuronal growth cone. Nature 244:93-96.

Bridgman PC, Kachar B, Reese TS (1986) The structure of cytoplasm in directly frozen cultured cells. II. Cytoplasmic domains associated with organelle movements. J Cell Biol 102:1510-1512.

Campenot RB (1977) Local control of neurite development by nerve growth factor. Proc Natl Acad Sci USA 74:4516-4519.

Campenot RB, Draker DD (1989) Growth of sympathetic nerve fibers in culture does not require extracellular calcium. Neuron 3:733-743.

Changeux J-P (1985) Neuronal man. New York: Oxford UP.

Cohan CS, Kater SB (1986) Suppression of neurite elongation and growth cone motility by electrical activity. Science 232:1638-1640.

Cohan CS, Connor JA, Kater SB (1987) Electrically and chemically mediated increases in intracellular calcium in neuronal growth cones. I Neurosci 7:3588-3599.

Connor JA (1986) Digital imaging of free calcium changes and of spatial gradients in growing processes in single mammalian central nervous system cells. Proc Natl Acad Sci USA 83:6179-6183.

Diaz J, Pecot-Dechavassine M (1989) Terminal nerve sprouting at the frog neuromuscular junction induced by prolonged tetrodotoxin blockade of nerve conduction. J Neurocytol 18:39-46.

Dodd J, Jessell TM (1988) Axon guidance and the patterning of neuronal projections in vertebrates. Science 242:692-699.

Fields RD, Yu C, Neale EA, Nelson PG (1988) Competition between convergent synapses in development: electrical activity modulates efficacy and number of inputs. Neurosci Abstr 14:178.

Fields RD, Neale EA, Nelson PG (1989a) Effects of electrical activity on outgrowth of neurites from mouse sensory neurons in vitro. J Cell Biol 107:729a.

Fields RD, LeBeau JM, Longo FM, Ellisman MH (1989b) Nerve regeneration through artificial tubular implants. Prog Neurobiol 33: 87-134.

Forscher P, Kaczmarek LK, Buchanan J, Smith SJ (1987) Cyclic AMP induces changes in distribution and transport of organelles within growth cones of Aplysia bag cell neurons. J Neurosci 7:3600-3611.

Forsythe ID, Coates RT (1988) A chamber for electrophysiological recording from cultured neurons allowing perfusion and temperature control. J Neurosci Meth 25:19-27.

Freeman JA, Manis PB, Snipes GJ, Mayes BN, Samson PC, Wikswo JP Jr, Freeman DB (1985) Steady growth conc currents rcvealed by a novel circularly vibrating probe: a possible mechanism underlying neurite growth. J Neurosci Res 13:257-284.

Gozes I, Barnstable CJ (1982) Monoclonal antibodies that recognize discrete forms of tubulin. Proc Natl Acad Sci USA 79:2579-2583.

Grinvald A, Farber IC (1981) Optical recording of calcium action potentials from growth cones of cultured neurons with a laser microbeam. Science 212:1164-1167.

Gunderson RW, Barrett JN (1980) Characterization of the turning response of dorsal root neurites toward nerve growth factor. J Cell Biol 87:546-554

Hagiwara S (1983) Membrane potential-dependent ion channels in cell membrane. Phylogenetic and developmental approaches. New York: Raven.

Hagiwara S, Byerly L (1981) Calcium channel. Annu Rev Neurosci $4: 69-125$

Harrelson AL, Goodman CS (1988) Growth cone guidance in insects: fasciclin II is a member of the immunoglobulin superfamily. Science 242:700-708.

Harris WA (1981) Neural activity and development. Annu Rev Physiol 43:689-710.

Haydon PG, McCobb DP, Kater SB (1984) Serotonin selectivity inhibits growth cone dynamics and synaptogenesis of specific ncurons of Heliosoma. Science 226:561-564. 
Hebb DO (1949) The organization of behavior. New York: Wiley.

Hille B (1984) Ion channels of excitable membranes. Sunderland, MA Sinauer.

Jia M, Nelson PG (1986) Calcium currents and transmitter output in cultured spinal and dorsal root ganglion neurones. J Neurophysiol $56: 1242-1256$

Kaczmarek LK, Strumwasser F (1981) The expression of long-lasting afterdischarge by isolated Aplysia bag cell neurons. J Neurosci 1:626634.

Kater S, Letourneau P (1985) Biology of nerve growth cone. J Neurosci Res 13:1-347.

Kater SB, Mattson MP, Cohan C, Connor J (1988) Calcium regulation of the neuronal growth cone. Trends Neurosci 11:315-321.

Koonce M, Schliwa M (1985) Bidirectional organelle transport can occur in cell processes that contain single microtubules. J Cell Biol 100:322-326

Kostenko MA, Musienko VS, Smolikhina TI (1983) Calcium and pH affect neurite formation in cultured mollusc isolated neurones. Brain Res 272:43-50.

Letourneau PC (assisted by Ressler AH) (1983) Differences in the organization of actin in the growth cones compared with the neurites of cultured neurons from chick embryos. J Cell Biol 97:963-973.

Letourneau PC (1985) Axonal growth and guidance. In: Molecular bases of neural development (Edelman GM, Gall WE, Cowan WM, eds), pp 269-293. New York: Wiley.

Letourneau PC (1987) What happens when growth cones meet neurites: attraction or repulsion? Trends Neurosci 10:390-393.

Levy WB, Desmond NL (1985) The rules of elemental synaptic plasticity. In: Synaptic modification, neuron selectivity, and nervous system organization, pp 105-122. Hillsdale, NJ: Erlbaum.

Llinas RR (1979) The role of calcium in neuronal function. In: The Neurosciences Fourth Study Program (Schmitt FO, Worden FG, eds), pp 555-571. Cambridge, MA: MIT.

MacVicar BA, Llinas RR (1985) Barium action potentials in regenerating axons of the lamprey spinal cord. J Neurosci Res 113:323336.

Mattson MP, Kater SB (1987) Calcium regulation of neurite elongation and growth cone motility. J Neurosci 7:4034-4043.

McCobb DP, Haydon PG, Kater SB (1988) Dopamine and serotonin inhibition of neurite elongation of different identified neurons. J Neurosci Res 19:19-26.

Miller RJ (1987) Multiple calcium channels and neuronal function. Science 235:46-52.

Neale EA, Fitzgerald SC, Bowers LM, Yu C, Fields RD, Nelson PG (1990) Multicompartment cell cultures for studies of neuronal interactions. In: Methods in neuroscience, vol 4 (Conn PM, ed). San Diego, CA: Academic Press (in press).

Neale EA, Koh J, Habig WH (1988) Fragment C of tetanus toxin is a non-toxic label for living neurons. Soc Neurosci Abstr 14:547.

Nelson PG, Yu C, Fields RD, Neale EA (1989) Synaptic connections in vitro: modulation of number and efficacy by electrical activity. Science 244:585-587.

Nelson PG, Fields RD, Yu C, Neale EA (1990) Mechanisms involved in activity-dependent synapse formation in mammalian central nervous system cell cultures. J Neurobiol 21:138-156.

Patterson PH (1988) On the importance of being inhibited, or saying no to growth cones. Neuron 1:263-267.

Purich DL, Terry BJ, White HD, Coughlin BA, Karr TL, Kristofferson D (1981) Microtubule associated protein phosphorylation and calcium-ion regulation of bovine brain microtubule self assembly. In: Cold Spring Harbor Conference on Cell Proliferation, No. 8, pp $1143-$ 1155. Cold Spring Harbor, NY: Cold Spring Harbor Laboratory.

Purves D, Lichtman JW (1983) Specific connections between nerve cells. Annu Rev Physiol 45:553-565.

Reuter H (1983) Calcium channel modulation by neurotransmitters, enzymes and drugs. Nature (Lond) 301:569-574.

Robbins N, Polak J (1988) Filopodia, lamellipodia and retractions at mouse neuromuscular junctions. J Neurocytol 17:545-561.

Schliwa M, Euteneuer U, Bulinski JC, Izant JC (1981) Calcium lability of cytoplasmic microtubules and its modulation by microtubule-associated proteins. Proc Natl Acad Sci USA 78:1037-1041.

Schmidt J, Tieman SB (1989) Activity, growth cones and the selectivity of visual connections. Comm Develop Neurobiol 1:11-28.

Schnapp BJ, Reese TS (1986) New developments in understanding rapid axonal transport. Trends Neurosci 9:155-162.

Shatz CJ (1990) Competitive interactions between retinal ganglion cells during prenatal development. J Neurobiol 21:197-211.

Smith SJ (1988) Neuronal cytomechanics: the actin-based motility of growth cones. Science 242:708-715.

Sokal RR, Rohlf FJ (1981) Biometry, 2nd ed. New York: Freeman.

Stent GS (1973) A physiological mechanism for Hebb's postulate of learning. Proc Natl Acad Sci USA 70:997-1001.

Strong JA (1984) Modulation of potassium current kinetics in bag cell neurons of Aplysia by an activator of adenylate cyclase. J Neurosci 4:2772-2783.

Strong JA, Kaczmarek LK (1986) Multiple components of delayed potassium current in peptidergic neurons of Aplysia: modulation by an activator of adenylate cyclase. J Neurosci 6:814-822

Thayer SA, Perney TM, Miller RJ (1988) Regulation of calcium homeostasis in sensory neurons by bradykinin. J Neurosci 8:4089-4097.

Torigoe K (1988) Terminal sprouting in partially denervated muscle of the mouse: a scanning electron microscopic study. J Neurocytol $17: 563-571$

Tsien RW (1983) Calcium channels in excitable cell membranes. Annu Rev Physiol 45:341-358.

Vallano ML, Goldenring JR, Buckholz TM, Larson RE, DeLorenzo R (1985) Separation of endogenous calmodulin- and cAMP-dependent kinases from microtubule preparations. Proc Natl Acad Sci USA 82: 3203-3206.

Weiss GB (1974) Cellular pharmacology of lanthanum. Annu Rev Pharmacol 14:343-354.

Yamamoto H, Fukunaga K, Tanaka E, Miyamoto E (1983) $\mathrm{Ca}^{2+}$ - and calmodulin-dependent phosphorylation of microtubule-associated protein 2 and tau factor, and inhibition of microtubule assembly. J Neurochem 41:1119-1125. 